BIOMEDICAL AND BIOSOCIAL ANTHROPOLOGY
$\begin{gathered}\text { Official Journal of the International Academy } \\ \text { of Integrative Anthropology } \\ \text { journal homepage: http://bba-journal.com }\end{gathered}$

\title{
Clinical significance of single nucleotide missense-mutation rs950880 of the IL1RL1 gene in patients with essential hypertension
}

Bahrij D. A.

National Pirogov Memorial Medical University, Vinnytsya, Ukraine

\section{ARTICLE INFO}

Received: 25 January 2021

Accepted: 26 February 2021

UDC: $575: 113.2: 616.12-07: 616.12-$

008.331 .1

\section{CORRESPONDING AUTHOR}

e-mail: dmitriybagriy@ukr.net Bahrij D. A.
Modern cardiology requires the search for specific pathogenetically involved gene mutations, the consequences of which can be considered in the management of patients with hypertension. Scientists are targeting C/A polymorphism at the rs950880 position, which is associated with tissue expression of the IL $1 R L 1$ gene and the plasma level of soluble ST2 - a new biomarker in the diagnosis of cardiovascular disease. The aim of the study was to evaluate the association of rs950880 polymorphism of the IL1RL1 gene and the state of central and intracardiac hemodynamics in men with essential hypertension (EH) of varying severity, residents of the Podillia region of Ukraine. 170 men who met the inclusion criteria were examined according to a standard protocol, which included clinical, laboratory and instrumental examinations in accordance with current recommendations. The subjects were divided into a control group of 70 men without cardiovascular disease and a study group of 50 men with asymptomatic $E H$ and 50 people with EH complicated by IIA stage chronic heart failure (CHF). Genotyping of SNP rs950880 of the IL1RL1 gene was performed using an allele-specific polymerase chain reaction. All men in the control group and the study group underwent echocardiography with Doppler according to the standard protocol. Statistical processing of the obtained results was performed in the package Statistica 12.0 using conjugation tables analysis, analysis of variance. It was found that among men living in Vinnytsia, Ukraine, carriers of CC and CA SNP rs950880 of the IL1RL1 gene dominate $(42.35 \%$ and $45.30 \%$ of individuals, respectively), AA homozygotes are significantly less common (12.53\%, $p<0.05)$. Men without cardiovascular diseases and patients with $E H$ do not differ significantly in the frequency of different variants of the genotype of the studied gene. C|A polymorphism is not associated with the risk of EH. The homozygotes $A A$ with $E H$ have a significantly lower LV myocardial mass index (LVMMI) $\left(69.14 \pm 6.90 \mathrm{~g} / \mathrm{m}^{2.7}\right.$, compared with homozygotes $C C-75.42 \pm 2.54 \mathrm{~g} / \mathrm{m}^{2.7}$, and heterozygotes $\left.C A-76.96 \pm 3.18 \mathrm{~g} / \mathrm{m}^{2.7}, p<0.05\right)$. Among the carriers of the $C$ allele, an "unfavorable" EH phenotype is mainly formed in the form of a high risk of $L V$ hypertrophy (OR=11.36, $95 \% C l=0.63-24.76, X^{2}=14.32, p=0.0008$ ). Homozygotes $A A$ in the rs 950880 locus of the IL1RL1 gene, on the contrary, have a low probability of developing LV hypertrophy $\left(O R=0.80,95 \% S I=0.02-0.42, X^{2}=14.32, p=0.0008\right)$ and its preserved systolic function. Thus, the SNP rs950880 of the IL1RL1 gene is not associated with the risk of EH or its severity in residents of Vinnytsia, Ukraine. Carriage of the $C$ allele is accompanied by the formation of an "unfavorable" EH phenotype with a significantly high risk of LV hypertrophy.

Keywords: soluble ST2, SNP rs950880 of the IL1RL1 gene, essential hypertension, left ventricular hypertrophy.

\section{Introduction}

The issues of developing effective strategies for the diagnosis and treatment of hypertension and its consequences have remained relevant for many decades, and are of great practical interest to physicians in many specialties. The urgency of the problem is due to the high incidence of hypertension with a high percentage of complications and fatalities associated with hypertensive damage to target organs, in particular, the formation of hypertensive heart. Virtually all known mechanisms of blood pressure (BP) regulation are under genetic control, and the probability of development and variants of left ventricular remodeling on the background of hypertension by $60 \%$ 
may be due to genetic factors [7]. The study of the genetic component of hypertension is carried out quite intensively, and the data are regularly updated. Quite interesting in this direction are the studies devoted to the study of SNP - single nucleotide polymorphisms. They are often associated with variability in the expression of genes encoding the activity and structure of biologically active substances that either stimulate or inhibit the mechanisms of heart remodeling in patients with hypertension. One of such substances is ST2 - a growth stimulating factor involved in the IL-33/ST2 system, which is responsible, inter alia, for cardioprotection [14]. To date, there are many studies that indicate an increase in the level of soluble ST2 in the plasma of patients with acute and chronic coronary heart disease, arterial systemic and pulmonary hypertension, heart disease, myocarditis, heart failure (HF) [2, 3, 5, 8, 12].

The ST2 gene is located on the 2 q12 human chromosome and is part of a large cluster of IL-1 genes (GenBank, number AC007248) [4]. It was found that C/A polymorphism (missense mutation with replacement of cytosine by alanine) at position rs950880 is associated with both the expression of the IL1RL1 gene in tissues and the plasma level of SST2 [9]. There is little data in the literature on the phenotypic implementation and clinical significance of the C/A polymorphism rs950880 of the IL1RL1 gene. In general, SNP rs950880 of the IL1RL1 gene locus has been studied in various populations in connection with bronchial asthma [10]. Only one study of this polymorphism in connection with cardiovascular pathology is known [11]. However, the needs of modern cardiology require the search for specific pathogenetically involved gene mutations, the consequences of which can be considered in the management of patients with hypertension.

Therefore, the aim of the study was to evaluate the association of rs950880 polymorphism of the IL1RL1 gene locus and indicators of central and intracardiac hemodynamics in men with essential hypertension $(E H)$ of varying severity, residents of the Podillia region of Ukraine.

\section{Materials and methods}

During study we examined 170 men according to a standard protocol, which included surveys, clinical, laboratory and instrumental examinations in accordance with current guidelines. Since the design was planned to analyze echocardiographic parameters, the standards of which may differ depending on sex, to create more homogeneous comparison groups in the study involved only persons of the same sex - men. Subjects were divided into a control group of 70 men without cardiovascular disease (mean age $48.82 \pm 0.78$ years), a study group that included 100 men with confirmed $\mathrm{EH}$ (mean age $50.17 \pm 0.48$ years). In the study group, 50 men were diagnosed with asymptomatic $\mathrm{EH}, 50$ people had $\mathrm{EH}$ complicated by HF IIA stage according to the classification of UAHFS (groups were representative by age), II-III f. class according to NYHA. EH stages were verified according to the recommendations of the European Society of Cardiology (ESC) and the European Society of Hypertension (ESH), 2018 [15]. Guided by the following inclusion criteria in the study: age from 40 to 60 years, male sex, verified by current recommendations diagnosis of $\mathrm{EH}$, living in the Vinnytsia region in the third generation, at a distance of more than $5 \mathrm{~km}$ from each other and no family ties with other participants in research (determined by questionnaires). Not included in the study in the presence of exclusion criteria: confirmed secondary hypertension, endocrine diseases, diseases of the blood system, chronic obstructive pulmonary disease, renal, hepatic impairment, available data from the history and documents on $\mathrm{EH}$ complications (myocardial infarction, acute disorders cerebral circulation), symptoms of stable angina III-IV functional classes or unstable forms of coronary heart disease (CHD), anamnestic indications for coronary heart disease, the development of which preceded the emergence of $\mathrm{EH}$. All study participants signed an Informed Consent to participate in the research and the processing of personal data before beginning any research procedures.

All study participants were determined polymorphism SNR rs950880 gene IL1RL1 using polymerase chain reaction $(P C R)$ with the involvement of the Research Institute of Genetic and Immunological Foundations of Pathology and Pharmacogenetics of the Ukrainian Medical Dental Academy, Poltava, director of the institute - PhD, senior researcher Shlykova O. A.

Also, all men in the control group and the study group underwent echocardiography with Doppler according to the standard protocol. Left ventricular myocardial mass (LVMM) was calculated according to the generally accepted ASE formula. Left ventricular hypertrophy (LVH) according to the results of echocardiography in men was diagnosed with LVMMI $\geq 115 \mathrm{~g} / \mathrm{m}^{2}$ or above $50 \mathrm{~g} / \mathrm{m}^{2.7}$ in case of obesity [15]. The state of LV systolic function was determined by the ejection fraction (LVEF). LVEF was considered reduced if the rate was $<40 \%$. Diastolic LV function was assessed according to the Recommendations of the American Society of Echocardiography and the European Association of Cardiovascular Imaging, 2016 [13].

Statistical processing of the obtained results was performed in the package Statistica 12.0 using the analysis of conjugation tables, analysis of variance. The significance of differences in the frequencies of observations according to Pearson's $x^{2}$ test and the significance of differences between groups according to Tukey's criteria were evaluated. The data obtained during the determination of the single nucleotide polymorphism of the rs950880 gene IL1RL1 were analyzed using a software calculator "CaseControl" (http://gen-expert.ru/calculator_or.php).

\section{Results}

According to the results of the study among men, residents of Vinnytsia region, allelic SNP rs950880 of the 


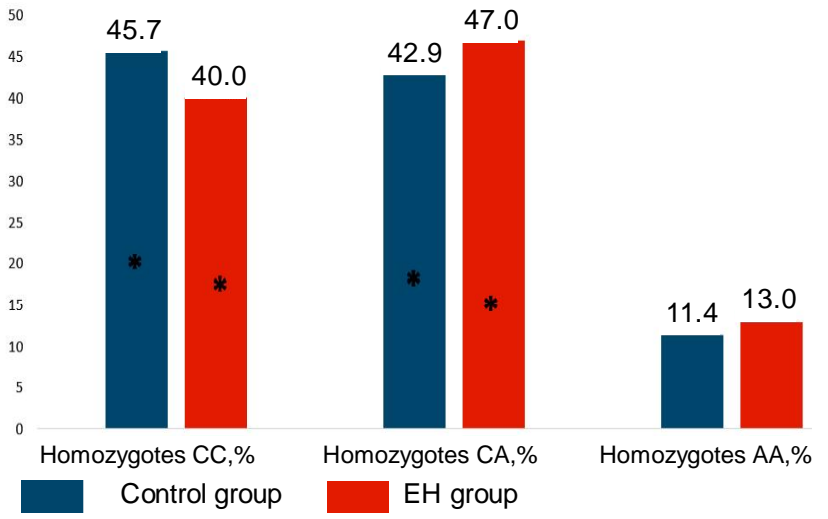

Fig. 1. Distribution of frequency variants of the SNP rs950880 genotype of the IL1RL1 gene among the residents of Vinnytsia region, (\%). * - the difference is significant in comparison with AA homozygotes, $\mathrm{p}<0.05$.

Table 1. Structural and functional parameters of the heart in patients with EH of men carrying SNP rs950880 gene IL1RL1, $(\mathrm{M} \pm \mathrm{m}, \%)$.

\begin{tabular}{|l|c|c|c|c|}
\hline \multicolumn{1}{|c|}{ Indexes } & $\begin{array}{c}1 . \\
\text { Homozygotes } \\
\text { CC }(n=40)\end{array}$ & $\begin{array}{c}2 . \\
\text { Heterozygotes } \\
\text { CA }(n=47)\end{array}$ & $\begin{array}{c}3 . \\
\text { Homozygotes } \\
\text { AA }(n=13)\end{array}$ & $p<0.05$ \\
\hline SBP, $\mathrm{mm} \mathrm{Hg}$ & $161.3 \pm 1,8$ & $162.9 \pm 1.7$ & $160.9 \pm 2.6$ & - \\
\hline DBP, $\mathrm{mm} \mathrm{Hg}$ & $99.58 \pm 0.97$ & $100.4 \pm 1.0$ & $102.1 \pm 2.1$ & - \\
\hline FDS, cm & $5.372 \pm 0.084$ & $5.329 \pm 0.071$ & $5.083 \pm 0.144$ & $p_{3-1}, p_{3-2}$ \\
\hline FSS, cm & $3.953 \pm 0.112$ & $3.891 \pm 0.092$ & $3.74 \pm 0.193$ & - \\
\hline TPVLV cm & $1.239 \pm 0.024$ & $1.251 \pm 0.024$ & $1.21 \pm 0.053$ & - \\
\hline TVV, cm & $1.241 \pm 0.019$ & $1.283 \pm 0.029$ & $1.254 \pm 0.057$ & - \\
\hline RWT, c.u. & $0.473 \pm 0.011$ & $0.481 \pm 0.014$ & $0.474 \pm 0.021$ & - \\
\hline FDI, ml/m & $68.45 \pm 2.37$ & $67.64 \pm 2.18$ & $62.90 \pm 3.97$ & - \\
\hline FSI, ml/m ${ }^{2}$ & $34.30 \pm 2.21$ & $33.89 \pm 1.88$ & $30.94 \pm 3.77$ & - \\
\hline $\mathrm{Sl}, \mathrm{ml} / \mathrm{m}^{2}$ & $34.14 \pm 1.04$ & $33,76 \pm 1,03$ & $31.96 \pm 1.74$ & - \\
\hline $\mathrm{LVMMl}$, & $75.42 \pm 2.54$ & $76.96 \pm 3.18$ & $69.14 \pm 6.90$ & $p_{3-1}, \mathrm{p}_{3-2}$ \\
\hline $\mathrm{g} / \mathrm{m}^{2,7}$ & $52.29 \pm 1.64$ & $51.17 \pm 1.56$ & $53.08 \pm 3.97$ & - \\
\hline $\mathrm{EF}, \%$ & $1.032 \pm 0.092$ & $0.932 \pm 0.061$ & $0.853 \pm 0.101$ & - \\
\hline $\mathrm{E} / \mathrm{A}, \mathrm{c} . \mathrm{u}$. & $4.168 \pm 0.113$ & $4.104 \pm 0.066$ & $4.018 \pm 0.177$ & - \\
\hline $\mathrm{LA}, \mathrm{cm}$ & $35.45 \pm 0.90$ & $35.89 \pm 0.62$ & $34.20 \pm 1.51$ & - \\
\hline $\mathrm{iVLA}, \mathrm{ml} / \mathrm{m}^{2}$ & & & & \\
\hline
\end{tabular}

IL1RL1 gene with allele A (35.0\%) and variant AA (12.4\%) are significantly less common than allele $\mathrm{C}(65.0 \%)$ and variants of genotype CC (42.4\%) and CA (45.3\%) ( $p<0.05)$.

When analyzing the prevalence of SNP rs950880 of the IL1RL1 gene in the control group and the group of patients with $\mathrm{EH}$, the following data were obtained (Fig. 1).

Moreover, the frequency of different variants of the genotype of the studied gene in men without cardiovascular disease and patients with EH do not differ significantly (see Fig. 1). Further analyzed the frequency distribution of SNP rs950880 of the IL1RL1 gene among men with EH of different severity and found that the nature of the prevalence of different variants of the studied SNP corresponds to the general population of men living in Vinnytsia. Thus, among patients with asymptomatic $\mathrm{EH}$ and $\mathrm{EH}$ complicated by $\mathrm{HF}$, carriers of the $\mathrm{C}$ allele are significantly more common (65.0\% and $62.0 \%$, respectively) than carriers of the A allele $(35.0 \%$ and $38.0 \%$, respectively, $\mathrm{p}<0.05)$. Among patients with asymptomatic $\mathrm{EH}, \mathrm{CC}$ homozygotes $42.0 \%$, CA heterozygotes $-46.0 \%$, and AA homozygotes significantly less $-12.0 \%$; in the $\mathrm{EH}$ group complicated by HF, the carriers of the variant CC $(38.0 \%)$ and the variant CA (48.0\%) predominate on the carriers of the variant of the AA genotype - $14.0 \%$. In general, for men living in Vinnytsia, the SNP rs950880 carrier of the IL1RL1 gene is not associated with an increased risk of developing $\mathrm{EH}\left(X^{2}=0.56, p=0.76\right)$.

At the next stage, the indicators of the structure and function of the heart (according to echocardiography) in carriers of different genotype variants among men without cardiovascular pathology, residents of Vinnytsia region were analyzed. It was found that all indicators of the structure and function of the heart are within normal limits and do not differ significantly in carriers of different genotype variants, and therefore the presence of allelic SNP rs950880 is not reflected in the structural and functional parameters of the heart in men. Next, we analyzed similar parameters in the group of patients with $\mathrm{EH}$ men (Table 1).

It was found that men with $\mathrm{EH}$ in the presence of a homozygous AA variant of SNP rs950880 have a significantly smaller final diastolic size (FDS) and a lower LV myocardial mass index (LVMMI). Blood pressure levels and other echocardiographic parameters in carriers of different genotype variants from the $\mathrm{EH}$ group did not differ significantly.

The next step was to study different heart remodeling options in patients with EH due to SNP rs950880. It turned out that LV hypertrophy in carriers of AA variant of the studied polymorphism is diagnosed significantly less often than in carriers of other variants of the genotype (Fig. 2).

At the same time, in carriers of different variants of SNP, concentric LVH is significantly more often detected (in $72.5 \%$ of patients CC homozygotes, $70.2 \%$ of patients CA heterozygotes and in $61.5 \%$ of patients AA homozygotes, $\mathrm{p} \geq 0.05$ ), which is quite characteristic of $\mathrm{EH}$.

In continuation of the analysis, we calculated the odds ratio (OR) to assess the risk of $\mathrm{LVH}$ in carriers of a certain variant of the SNP rs950880 genotype of the IL1RL1 gene

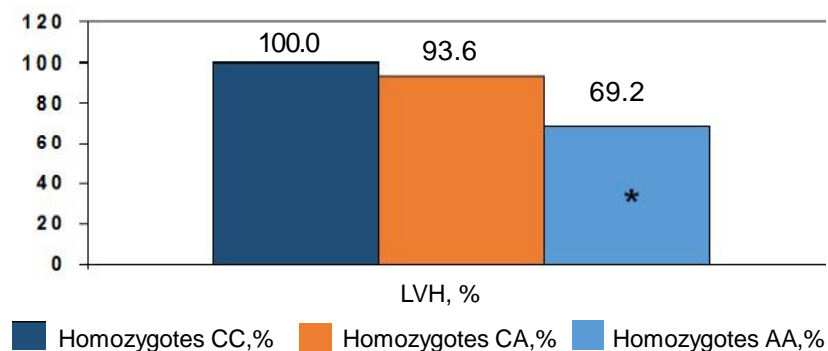

Fig. 2. The prevalence of LVH in patients with $\mathrm{EH}$ carriers of different variants of SNP rs950880.

Note: * - differences are significant when compared between groups, $p<0.05$. 
Table 2. Models of SNR rs950880 inheritance of the IL1RL1 gene due to LVH formation in patients with $\mathrm{EH}$ (chi-square test, $\mathrm{df}=1.2$ ).

\begin{tabular}{|l|c|c|c|c|c|c|}
\hline $\begin{array}{c}\text { Variants } \\
\text { of } \\
\text { genotype } \\
\text { allele }\end{array}$ & Case & Control & $X^{2}$ & $p$ & \multicolumn{2}{|c|}{ OR } \\
\cline { 2 - 3 } & $\mathrm{n}=93$ & $\mathrm{n}=7$ & & & Value & $95 \% \mathrm{Cl}$ \\
\hline CC & 0.430 & 0.00 & \multirow{4}{*}{14.32} & 0.0008 & 11.36 & $0.63-24.67$ \\
\hline CA & 0.473 & 0.429 & & & 1.20 & $0.25-5.65$ \\
\hline AA & 0.097 & 0.571 & & & 0.80 & $0.02-0.42$ \\
\hline
\end{tabular}

for men with $\mathrm{EH}$ (Table 2). In the calculations, the group "Case" included patients with EH and LVH, in the group "Control" - men with EH and without LVH.

Thus, for men with $\mathrm{EH}$, residents of Vinnytsia, carriers of the C SNP rs950880 allele of the IL1RL1 gene are associated with a significant risk of developing LV hypertrophy. Obviously, the phenotypic features of the SNP rs950880 of the IL1RL1 gene in patients with $\mathrm{EH}$ are probably realized in the form of changes in SST2 production and a higher risk of LVH formation.

Regarding the functional state of the heart in patients with EH carriers of different variants of the SNP rs950880 genotype, the following results were obtained. Diastolic dysfunction in patients with $\mathrm{EH}$ is formed with almost the same frequency in different allelic variants of SNP rs950880: among CC homozygotes in $87.5 \%$ of patients, among CA heterozygotes in $91.5 \%$ of patients and among $A A$ homozygotes in $92.3 \%$ of patients, $p \geq 0.05$.

When studying the indicators of left ventricular systolic function, it was found that in general patients with low left ventricular EF are rare among patients with $\mathrm{EH}$, and mostly carriers of CA and CC genotype variants - $15.0 \%$ and $14.9 \%$ of patients. Among AA-homozygotes, all patients had preserved LVEF.

\section{Discussion}

Biomarker strategy for the diagnosis of cardiovascular disease is becoming increasingly popular. In many clinical studies, the potential for the use of soluble SST2 for diagnostic and prognostic purposes has been convincingly demonstrated [3, 2, 6, 8, 12]. In our previous study, it was found that in patients with $\mathrm{EH}$, the level of SST2 significantly increases due to the formation of LV hypertrophy, the development of HF [5]. However, there are currently studies whose results indicate significant differences in peptide production due to point mutations in the ST2 gene, which is part of the IL-1 gene cluster [4]. It is for the C/A polymorphism rs950880 that the most pronounced association with the plasma level of SST2 has been established, and it has been shown that the level of peptide in the blood of CC homozygotes is $43 \%$ higher than that of AA homozygotes [9]. Therefore, we can expect other features of the phenotypic implementation of SNP rs950880, in particular, in essential hypertension.

In general, studies of the prevalence of SNP rs950880 of the IL1RL1 gene in other populations are few. Data from
Taiwanese scientists are available for analysis, with whom we compared our results (Table 3) [11].

It turned out that the prevalence of SNP rs950880 among Ukrainians and Taiwanese has similar characteristics: both populations are dominated by carriers of the $C$ allele, and the variant of the AA genotype is determined least often. However, there are some population differences: CC homozygotes among Taiwanese are significantly less common than in Vinnytsia, Ukraine.

The rs950880 single nucleotide polymorphism has been studied in connection with inflammatory diseases of the respiratory system. In particular, a reliable association of rs950880 C/A polymorphism with the development of bronchial asthma and atopy was established for Canadians [4]. Regarding the main cardiovascular diseases, there are no data, although the need to study the phenotypic implementation of the gene encoding such a promising biomarker is certainly there. The available results showed that the rs950880 C/A polymorphism was not significantly associated with the risk of recurrent venous thrombosis or pulmonary embolism, or mortality in patients with chronic postthromboembolic pulmonary hypertension [1]. It has also been established that the carrier of the $A A$ genotype variant is an independent predictor of overall mortality in patients with atherosclerosis of the coronary and peripheral arteries, however, it is not associated with the risk of cardiovascular death [11].

Therefore, our study showed for the first time that in patients with $\mathrm{EH}$ carriers of different variants of SNP rs950880 of the IL1RL1 gene, the formation of certain phenotypes of myocardium remodeling is observed. Thus, patients with the $\mathrm{C}$ allele have more pronounced structural and functional changes in the myocardium compared with carriers of the $A$ allele. Carriers of the $C$ allele men with $E H$ are associated with a significantly higher probability of LVH formation, significantly more frequent violation of LV systolic function, while in patients with EH homozygotes AA LV hypertrophy and systolic dysfunction are less common.

The data obtained during the study may allow the development of individual management strategies for patients with essential hypertension, taking into account the found features of the phenotypic implementation of the SNP rs950880 gene IL1RL1.

Table 3. Distribution of frequency variants of the SNP rs 950880 genotype of the IL1RL1 gene in different populations, (\%).

\begin{tabular}{|l|c|c|c|c|}
\hline \multicolumn{1}{|c|}{ Source } & $\begin{array}{c}1 . \\
\text { Homozygotes } \\
\text { CC }\end{array}$ & $\begin{array}{c}2 . \\
\text { Heterozygotes } \\
\text { CA }\end{array}$ & $\begin{array}{c}3 . \\
\text { Homozygotes } \\
\text { AA }\end{array}$ & $p<0.05$ \\
\hline $\begin{array}{l}\text { 1. Vinnytsia } \\
\text { region } \\
\text { (own data), } \\
\text { (n=170) }\end{array}$ & 42.35 & 45.30 & 12.53 & $\begin{array}{c}p_{3-1} \\
p_{3-2}\end{array}$ \\
\hline $\begin{array}{l}\text { 2. Taiwan } \\
\text { [11], } \\
(n=1219)\end{array}$ & 30.52 & 50.62 & 18.46 & $\begin{array}{l}p_{3-1} \\
p_{3-2,} \\
p_{2-1}\end{array}$ \\
\hline$p$ & $<0.01$ & $\geq 0.05$ & $<0.05$ & \\
\hline
\end{tabular}




\section{Conclusion}

1. Carriers of the C SNP rs950880 allele of the IL1RL1 gene dominate among men living in Vinnytsia. The studied polymorphism is not associated with either the risk of $\mathrm{EH}$ or its severity.

2. Carrier of the $\mathrm{C}$ allele is accompanied by the formation of an "unfavorable" EH phenotype with a significantly high

\section{References}

[1] Ahmad, A., Sundquist, K., Palmr, K., Svensson, P. J., Sundquist, J., \& Memon, A. A. (2019). Risk prediction of recurrent venous thromboembolism: a multiple genetic risk model. Journal of Thrombosis and Thrombolysis, 47, 216-226. doi: 10.1007/ s11239-018-1762-7

[2] Aimo, A., Maisel, A. S., Castiglione, V., \& Emdin, M. (2019). sST2 for outcome prediction in acute heart failure: which is the best cutoff?. Journal of the American College of Cardiology, 74(3), 478-479. doi: 0.1016/j.jacc.2019.03.527

[3] Aleksova, A., Paldino, A., Beltrami, A. P., Padoan, L., lacoviello, M., Sinagra, G., ... \& Maisel, A. S. (2019). Cardiac biomarkers in the emergency department: the role of soluble ST2 (sST2) in acute heart failure and acute coronary syndrome - there is meat on the bone. Journal of clinical medicine, 8(2), 270279. doi: 10.3390/jcm8020270

[4] Baba, Y., Maeda, K., Yashiro, T., Inage, E., Kasakura, K., Suzuki, R., ... \& Nishiyama, C. (2012). GATA2 is a critical transactivator for the human IL1RL1/ST2 promoter in mast cells/basophils: opposing roles for GATA2 and GATA1 in human IL1RL1/ST2 gene expression. Journal of Biological Chemistry, 287(39), 32689-32696. https://doi.org/10.1074/jbc.M112.374876

[5] Bahrij, D. A., Starzhynska, O. L., \& Zhebel, V. M. (2020). Концентрація розчинного ST2 у плазмі крові та дисфункція серця в пацієнтів з есенціальною гіпертензією [Concentration of soluble ST2 and heart dysfunction in hypertensive patients]. Український кардіологічний журнал - Ukrainian Journal of Cardiology, 27(5), 53-59. doi: 10.31928/ 1608-635X-2020.5.5359

[6] Bi, J., Garg, V., \& Yates, A. R. (2021). Galectin-3 and sST2 as Prognosticators for Heart Failure Requiring Extracorporeal Life Support: Jack n'Jill. Biomolecules, 11(2), 166. doi: 10.3390/ biom11020166

[7] Evangelou, E., Warren, H. R., Mosen-Ansorena, D., Mifsud, B., Pazoki, R., Gao, H., ... \& Lind, L. (2018). Genetic analysis of over 1 million people identifies 535 new loci associated with blood pressure traits. Nature genetics, 50(10), 1412-1425. doi: 10.1038/s41588-018-0205-x

[8] Farcas, A. D., Anton, F. P., Goidescu, C. M., Gavrila, I. L., VidaSimiti, L. A., \& Stoia, M. A. (2017). Serum soluble ST2 and diastolic dysfunction in hypertensive patients. Disease markers, (5), 1-8. doi: 10.1155/2017/2714095

[9] Ho, J. E., Chen, W. Y., Chen, M. H., Larson, M. G., McCabe, E. L., Cheng, S., ... \& Wang, T. J. (2013). Common genetic variation at the IL1RL1 locus regulates IL-33/ST2 signaling. The Journal of clinical investigation, 123(10), 4208-4218. doi: 10.1172/ risk of LV hypertrophy.

3. The presence of a variant of the AA genotype in the locus rs950880 of the IL1RL1 gene, on the contrary, is associated with a light variant of cardiac remodeling with a significantly low probability of LV hypertrophy and preservation of its systolic function.

JCl67119

[10] Johansson, A., Rask-Andersen, M., Karlsson, T., \& Ek, W. E. (2019). Genome-wide association analysis of 350000 Caucasians from the UK Biobank identifies novel loci for asthma, hay fever and eczema. Human molecular genetics, 28(23), 4022-4041. doi: 10.1093/hmg/ddz175

[11] Lin, J. F., Wu, S., Juang, J. M. J., Chiang, F. T., Hsu, L. A., Teng, M. S., ... \& Ko, Y. L. (2017). IL1RL1 single nucleotide polymorphism predicts SST2 level and mortality in coronary and peripheral artery disease. Atherosclerosis, 257(2), 7177. doi: 10.1016/j.atherosclerosis.2016.12.020

[12] Maupoint, J., Richard, V., Vallet, C., Albrecht, C., Ouchani, F., Eltchaninoff, H., \& Bauer, F. (2016, August). Correlation between ST2 levels, Doppler echocardiographic parameters and prognosis in patients with heart failure and preserved ejection fraction. In European heart journal (Vol. 37, pp. 716716). Great Clarendon St, Oxford OX2 6DP, England: Oxford Univ Press.

[13] Nagueh, S. F., Smiseth, O. A., Appleton, C. P., Byrd, B. F., Dokainish, H., Edvardsen, T., ... \& Houston, Texas; Oslo, Norway; Phoenix, Arizona; Nashville, Tennessee; Hamilton, Ontario, Canada; Uppsala, Sweden; Ghent and Liege, Belgium; Cleveland, Ohio; Novara, Italy; Rochester, Minnesota; Bucharest, Romania; and St. Louis, Missouri. (2016). Recommendations for the evaluation of left ventricular diastolic function by echocardiography: an update from the American Society of Echocardiography and the European Association of Cardiovascular Imaging. European Journal of Echocardiography, 17(12), 1321-1360. doi: 10.1016/ j.echo.2016.01.011

[14] Schmitz, J., Owyang, A., Oldham, E., Song, Y., Murphy, E., McClanahan, T. K., ... \& Kastelein, R. A. (2005). IL-33, an interleukin-1-like cytokine that signals via the IL-1 receptorrelated protein ST2 and induces T helper type 2-associated cytokines. Immunity, 23(5), 479-490. doi: 10.1016/ j.immuni.2005.09.015

[15] Whelton, P. K., Carey, R. M., Aronow, W. S., Casey, D. E., Collins, K. J., Dennison Himmelfarb, C., ... \& Wright, J. T. (2018). 2017 ACC/AHA/AAPA/ABC/ACPM/AGS/APhA/ASH/ASPC/ NMA/PCNA guideline for the prevention, detection, evaluation, and management of high blood pressure in adults: a report of the American College of Cardiology/American Heart Association Task Force on Clinical Practice Guidelines. Journal of the American College of Cardiology, 71(19), e127-e248. doi: 10.1161/HYP.0000000000000065 